\title{
Seismic behaviour of a large-scale concrete-block retaining wall
}

\author{
Noboru Sato ${ }^{1,}$, Toshikazu Sawamatsu ${ }^{1}$, Takehiko Nitta $^{1}$, Hiroaki Miyatake ${ }^{1}$, and Kazuhito Kondo ${ }^{2}$ \\ ${ }^{1}$ Public Works Research Institute, Ibaraki, Japan \\ ${ }^{2}$ Japan Concrete Block Industries Association, Tokyo, Japan
}

\begin{abstract}
In this study, an inclined model experiment and finite element analyses were conducted to evaluate the failure mode and seismic response of a dry-type large-scale concrete-block retaining wall (LCBW). In the experiment, the objective was to reproduce the sliding between concrete blocks that was observed in past cases LCBW damage in order to characterise the behaviour until failure. A numerical simulation corresponding to the experimental conditions was conducted by the finite element method (FEM). Dynamic analyses were also performed by FEM to investigate the seismic response of the concrete blocks under various ground conditions. The experimental results revealed that slip between the concrete blocks caused brittle failure of the LCBW. In the FEM simulation, the joint elements reproduced the experimentally observed sliding between the concrete blocks. A dynamic simulation of the full-scale model revealed that significant sliding and rocking of the concrete block occur in a dry-type LCBW. These findings indicate that stress concentration may occur at the heels of the concrete blocks during an earthquake.
\end{abstract}

\section{Introduction}

In Japan, various nationwide efforts have been made to improve productivity. Utilising precast concrete products improves the efficiency of public works projects. There are many different types of precast concrete products for road earth structures including retaining walls, culverts, etc. Therefore, it is necessary to carefully select the most suitable product in consideration of the site conditions to ensure the performance requirements are met. On the other hand, the main materials used in earthen road structures, soil and rock, are very heterogeneous and are associated with a high level of uncertainty. Therefore, it is important to not only conduct design calculations but also analyse failed structures.

Damaged precast retaining walls, such as large-scale concrete-block retaining walls (LCBWs), have been investigated and analysed in prior studies [1]. According to the literature, dry-type LCBWs (in which the blocks are not bound with concrete) were more easily deformed than wet-type LCBWs (in which concrete is added between the blocks). The deformation modes in dry-type LCBWs was classified into some categories in prior studies [1]: sliding between concrete blocks, damaged to a concrete block, rotation of concrete blocks etc. (Fig. 1). Sliding between concrete blocks is the most likely deformation to affect the stability of an LCBW.

In this study, an inclined model experiment and a finite element method (FEM) simulation were conducted in order to clarify the failure modes of dry-type LCBWs and the seismic responses exhibited by concrete blocks. In the experiment, damage due to sliding between concrete blocks was reproduced as observed from a past

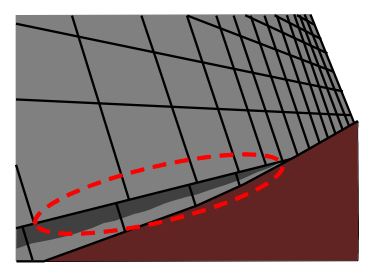

a) Sliding between concrete blocks in out-of-plane direction.

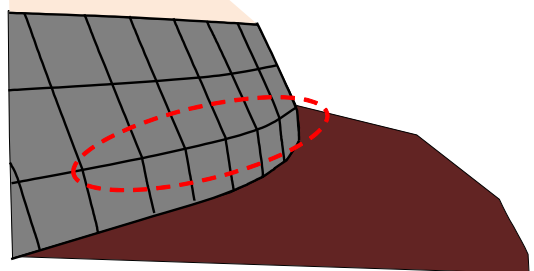

b) Bulging deformation due to damage to bottom concrete blocks.

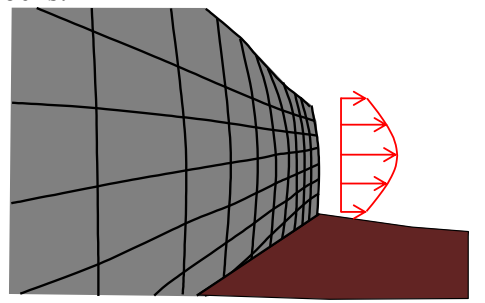

c) Bulging deformation due to rotation of concrete block.

Fig. 1. The deformation modes in dry-type LCBWs. [1]

case of LCBW damage due to an earthquake. Moreover, a two-dimensional (2D) numerical FEM simulation was conducted based on the experimental conditions. Further, dynamic FEM analysis was carried out to evaluate the

\footnotetext{
* Corresponding author: n-sato44@pwri.go.jp
} 
seismic response of a concrete block under various ground conditions.

a) Inclined experiment model.

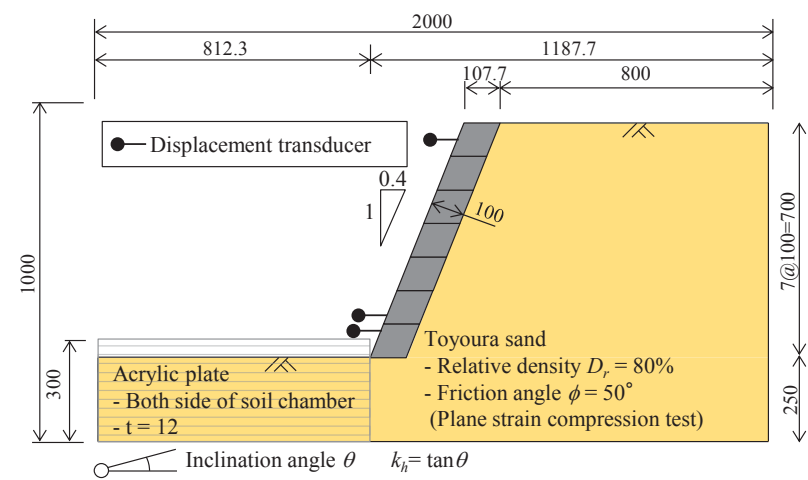

b) Simulation model

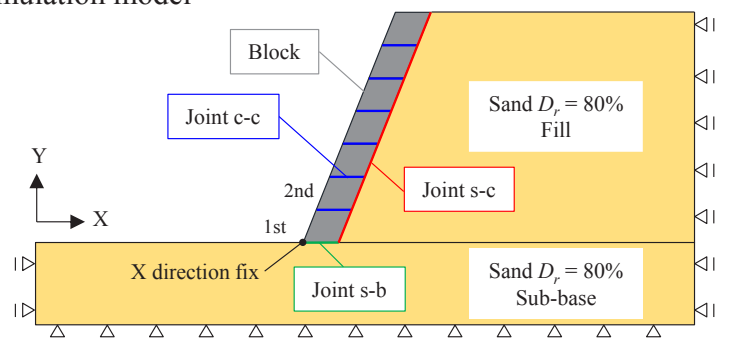

Fig. 2. Schematic diagram of experiment and simulation model.

\section{Inclined model experiment of LCBW and numerical simulation}

\subsection{Experiment procedures}

An LCBW model with a height of $700 \mathrm{~mm}$, thickness of $100 \mathrm{~mm}$ and inclination of 1:0.4 was prepared in a soil chamber with a height of $1000 \mathrm{~mm}$, length of $2000 \mathrm{~mm}$ and depth of $500 \mathrm{~mm}$ (Fig. 2). The geometric shape of the model was determined based on those of LCBWs that were damaged by earthquakes and the Japanese guidelines for retaining walls [2] at a scale of about 1:10. The block models were made of mortar using steel formwork. Each block model was a parallelogram and there was no interlocking between the blocks. In order to generate uniform friction on the surfaces of the block models, sand paper was attached to the block surfaces, resulting in a friction coefficient of 0.62 between blocks. Air-dried Toyoura sand was used; the sand was clean, fine and fairly uniform and it had a soil particle density of 2.64 $\mathrm{g} / \mathrm{cm}^{3}$, uniformity coefficient, $D_{60} / D_{10}$, of 1.3 , mean diameter, $D_{50}$, of $0.2 \mathrm{~mm}$, maximum void ratio $e_{\max }$ of 0.977 , and minimum void ratio, $e_{\min }$, of 0.605 . The ground of the model was compacted at depth intervals of $100 \mathrm{~mm}$ to achieve an average relative density of $80 \%$. In cases when a LCBW was damaged due to earthquake, deformation of the ground in front of the wall was not observed; in order to reproduce this condition, the bottom concrete block was restrained using acrylic plates as shown in Fig. 2 a) to prevent lateral movement. Two Teflon sheets were placed between the block and the

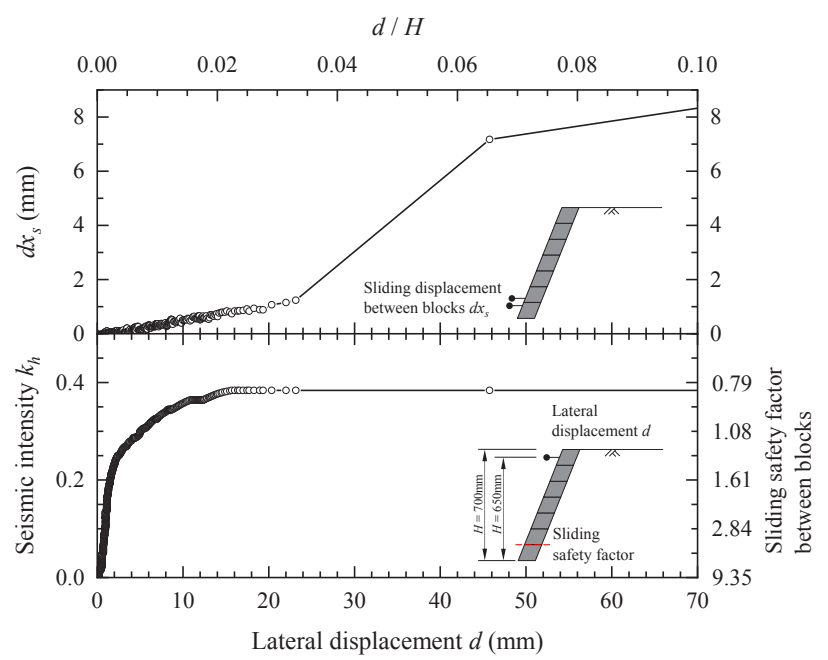

Fig. 3. Horizontal displacement, $d$, at a height of $650 \mathrm{~mm}$, the sliding displacement $d x_{s}$ between the first and second blocks, the horizontal seismic intensity, $k_{h}$, and the sliding safety factor between the first and second blocks.

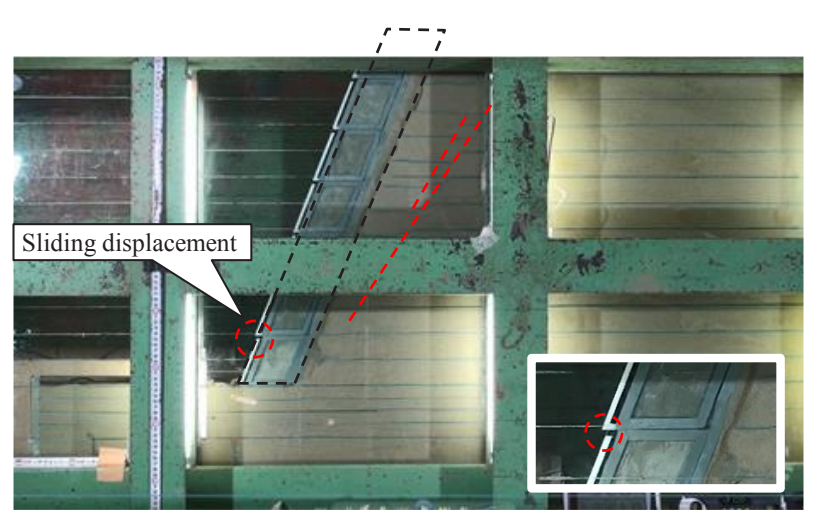

Fig. 4. Test result showing the deformation. $\left(k_{h}=0.36\right)$

acrylic plate to reduce the friction between them as much as possible.

In Japan, in the seismic design of earthen road structures and the corresponding retaining walls, the dynamic load from the earthquake ground motion is replaced by the equivalent static horizontal force in order to perform steady-state calculations. In this test, the horizontal force that represents the seismic force was introduced to the model by inclining the soil chamber [3]. The magnitude of the horizontal force was represented by the horizontal seismic intensity, $k_{h}$, in the inclined model experiment. The relationship between the $k_{h}$ value and the inclination angle of the soil chamber, $\theta$, was expressed as $k_{h}=\tan \theta$. The inclination rate of the soil chamber was set to $1 \% \mathrm{~min}$ and the inclined state was maintained for $1 \mathrm{~min}$ at every $1^{\circ}$ increment in order to cause creep deformation in the model. The displacements of the wall were measured by displacement transducers as shown in Fig. 2 a).

\subsection{Experimental results}

Figure 3 shows the horizontal displacement, $d$, at a height of $650 \mathrm{~mm}$, the sliding displacement between the first and second blocks from the bottom, the horizontal seismic intensity, $k_{h}$, and sliding safety factor based on design 
calculation at the between first and second blocks. Fig. 4 shows the locations of the blocks and the ground in the model after displacement. The overturning of the LCBW model was prominent until the $k_{h}$ value reached 0.38 . The sliding displacement between the blocks, $d x_{s}$, increased linearly until it reached $1 \mathrm{~mm}$ then rapidly increased until it reach $7 \mathrm{~mm}$, at which time the LCBW model failed. Therefore, it was concluded that the sliding between the blocks rapidly causes instability in the retaining wall. This finding suggests that protrusions or interlocks should be arranged to ensure integrity at the interfaces between the blocks.

\subsection{Simulation of the inclined model experiment}

The inclined model experiment was simulated using a total-stress static analysis in a 2D-plane in the strain state. Figure $2 \mathrm{~b}$ ) and Table 1 show the simulation model and the parameters, respectively. Joint s-c is a joint element between the sand and the concrete block, Joint s-b is a joint element between the sand and the bottom of the concrete block, and Joint c-c is a joint element between the concrete blocks. The sand was represented by a MohrCoulomb model and the concrete blocks exhibited linear elasticity. The mechanical parameters of the Toyoura sand were as follows: the shear resistance angle, $\phi$, was $50.2^{\circ}$ and the Young's modulus, E, was $12531 \mathrm{kN} / \mathrm{m}^{2}$ (Both values obtained from a plane strain compression test of Toyoura sand under a low confined pressure [4]). A nonlinear joint element was used to represent the slide and separation between the blocks and between the block and the ground. The parameters of the joint elements were obtained from friction tests. In the friction test, a block placed on another block fixed on inclinable base. And friction coefficent was obtaied from the angle which block started to slide by inclining the base. The horizontal forces due to the inclination in the experiment were introduced statically in the simulation. The restriction of the bottom block by acrylic plates in the experiment was represented by fixing the X-direction freedom of the toe of the bottom block.

\subsection{Simulation result}

Figure 5 shows the simulated deformation at a $k_{h}$ value of 0.36 . The observed sliding behaviour between blocks was similar to that observed the experiment. The slip line in the backfill was generated from the sliding second block and exhibited a tendency similar to that observed in the experiment. Hence, it was confirmed that the behaviour of the blocks was reproduced appropriately by using joint elements in this LCBW simulation.

\section{Simulating seismic behaviour in a full- scale model}

\subsection{Simulation procedure}

In order to clarify the seismic response of concrete blocks, dynamic analyses were carried out by the FEM with a fullscale LCBW model. A full-scale LCBW model with a
Table.1 Simulation parameters in the inclined model experiment.

\begin{tabular}{lccc|c|c|c}
\hline & & & \multicolumn{2}{|c|}{$\begin{array}{c}\text { Sand } D r=80 \% \\
\text { Fill }\end{array}$} & $\begin{array}{c}\text { Sand } D r=80 \% \\
\text { Sub-base }\end{array}$ & Block \\
\hline \hline Constitutive model & & & \multicolumn{2}{|c|}{ Mohr-Coulomb } & Linear elastic \\
\hline Density & $\gamma$ & $\mathrm{kN} / \mathrm{m}^{3}$ & 15.66 & 15.66 & 18.58 \\
\hline Cohesion & $c$ & $\mathrm{kN} / \mathrm{m}^{2}$ & 0 & 0 & - \\
\hline Friction angle & $\phi$ & $\mathrm{deg}$. & 50.2 & 50.2 & - \\
\hline Poisson ratio & $v$ & & 0.17 & 0.17 & 0.3 \\
\hline Young's modulus & $E$ & $\mathrm{kN} / \mathrm{m}^{2}$ & 12531 & 12531 & 23500000 \\
\hline \hline Joint element & \multicolumn{1}{c|}{} & $\mathrm{s}-\mathrm{c}$ & $\mathrm{S}-\mathrm{b}$ & $\mathrm{c}-\mathrm{c}$ \\
\hline Normal stiffness & $k n$ & $\mathrm{kN} / \mathrm{m}^{3}$ & $1.0 \times 10^{9}$ & $1.0 \times 10^{9}$ & $1.0 \times 10^{9}$ \\
\hline Shear stiffness & $k t$ & $\mathrm{kN} / \mathrm{m}^{3}$ & $1.0 \times 10^{-1}$ & $1.0 \times 10^{5}$ & $1.0 \times 10^{5}$ \\
\hline Friction angle & $\phi$ & $\mathrm{deg}$. & 33.5 & 31.0 & 32.3 \\
\hline
\end{tabular}

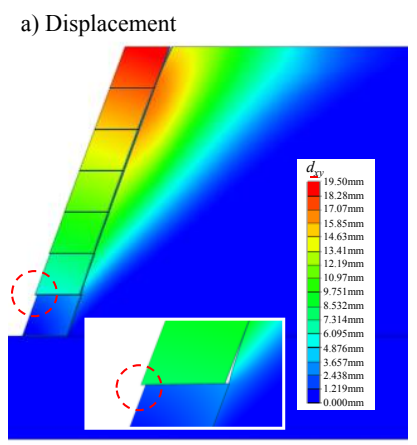

b) Maximum shear strain

Fig. 5. Simulated deformation. $\left(k_{h}=0.36\right)$

height of $7 \mathrm{~m}$, thickness of $0.75 \mathrm{~m}$ and inclination of 1:0.5 was simulated (Fig. 6). The shape of the model was determined with reference to a case of LCBWs that were damaged by earthquake and the Japanese guideline for retaining walls [2]. In the guideline, combinations of height, inclination, and thickness of LCBW is determined based on past experiences and achievements. LCBWs are applied only to conditions with small earth pressure; fully compacted fill or stable cut slope. The parameters of the simulation were varied to model consider different ground to know the influence on the LCBW by the ground. In order to simplify, nonlinear total stress dynamic analysis was performed in a $2 \mathrm{D}$ plane strain state without considering the influence of pore water pressure. The initial stress state was obtained using static analysis by applying the acceleration due to gravity to the simulation model. Then, the deformation and strain were reset before the dynamic analysis. The dynamic analysis was performed assuming the initial stress state. The dynamic response was elicited by applying a horizontal acceleration to the simulation model and solving the time history response by the direct integration method. Fig. 6 shows the simulation model. Two types of LCBWs, the dry-type and the wet-type were assumed and their behaviours were compared. The dry-type LCBW was expressed by using non-linear joint element between the blocks while the wet-type LCBW was reproduced by merging the nodes between blocks. Table 2 shows the simulation parameters. The parameters of ground behind the LCBW were assumed to be those of cohesive soil, sandy soil or gravelly soil. The ground behind the 

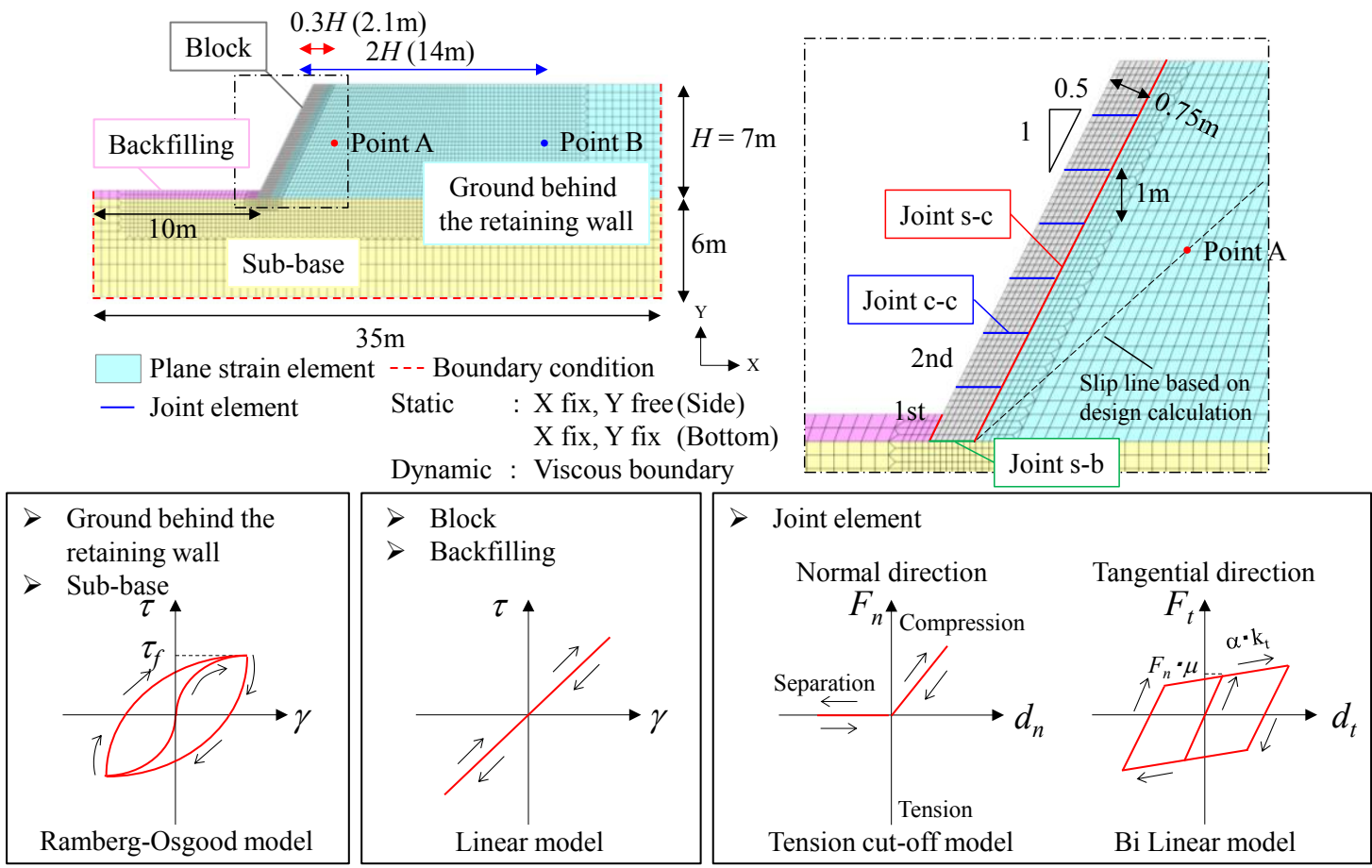

Fig. 6. Full-scale simulation model.

Table. 2. Full-scale model simulation parameters.

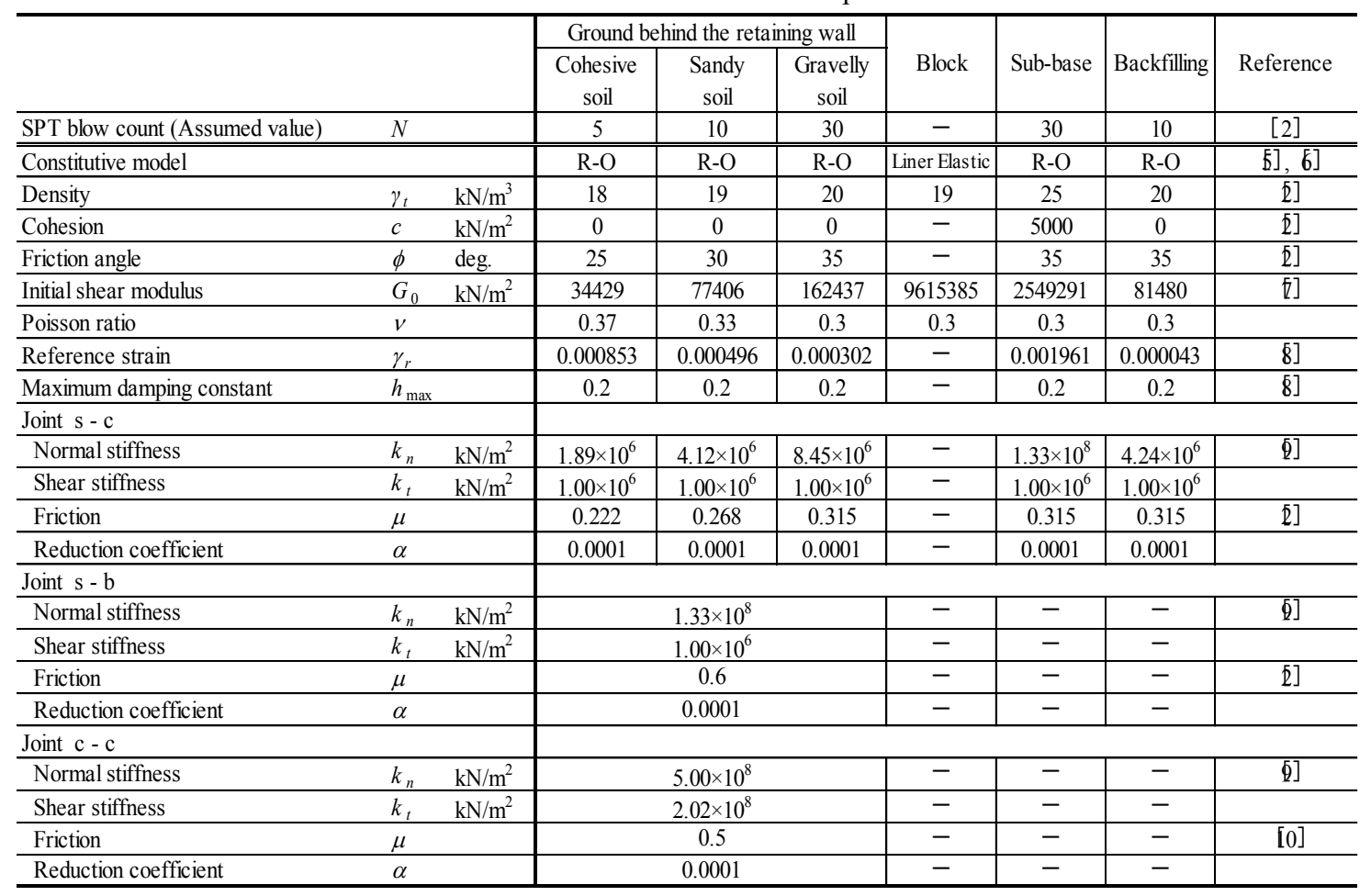

retaining wall and sub-base were modelled using modified the Ramberg-Osgood model (R-O model) $[5,6]$. $\mathrm{R}-\mathrm{O}$ model is easily to use as it requires only three parameters; The reference strain $\gamma_{\mathrm{r}}$, maximum damping constant $h_{\max }$, and the Initial shear modulus $G_{0}$. A hysteresis curve is obtained based on Masing's rule. A linear elastic model was used for the concrete blocks. Two-node non-linear joint elements were used to model the interactions between two concrete blocks and those

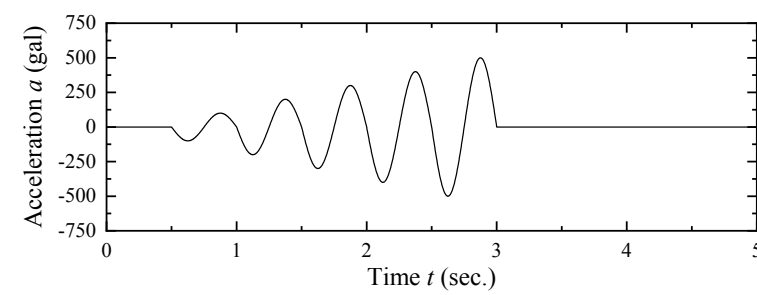

Fig. 7. Input acceleration. 


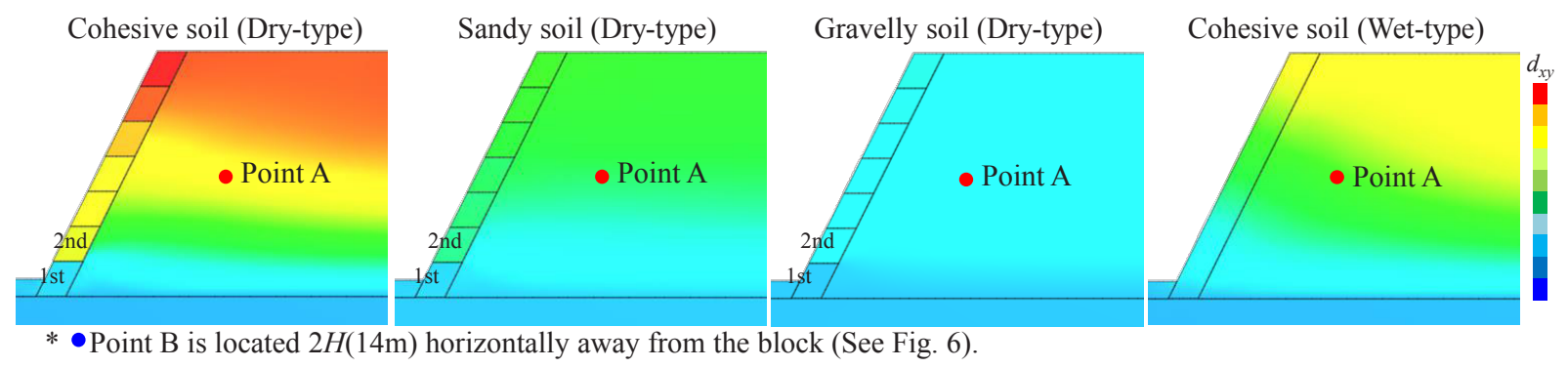

Fig. 8. Contour of maximum response displacement
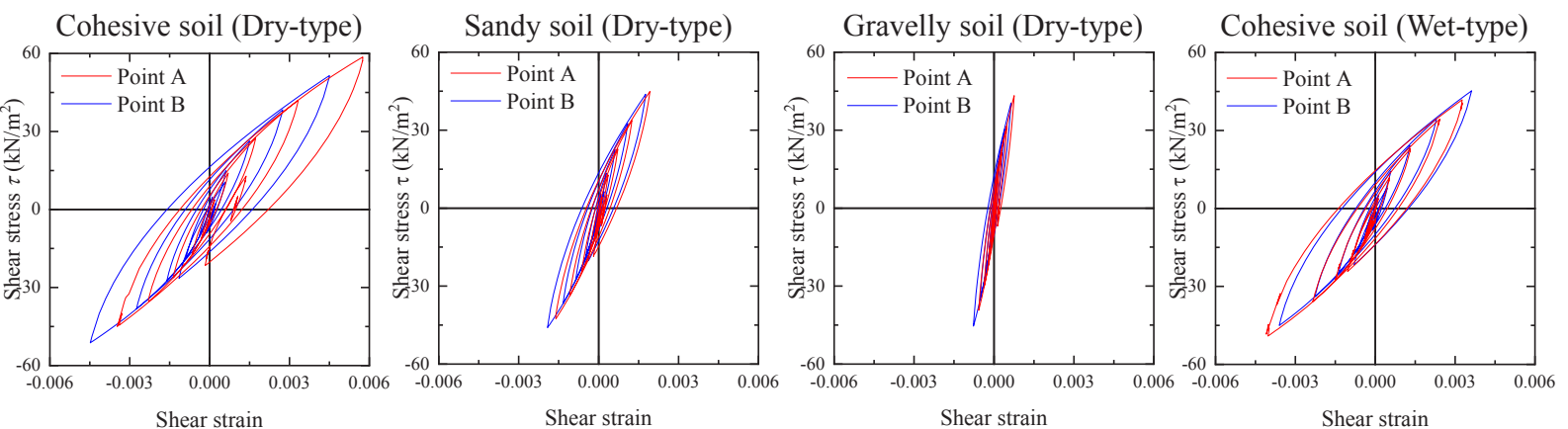

Fig. 9. Relationship between shear stress and shear strain at $0.3 H(2.1 \mathrm{~m})$ and $2 H(14 \mathrm{~m})$ horizontally away from the LCBW.

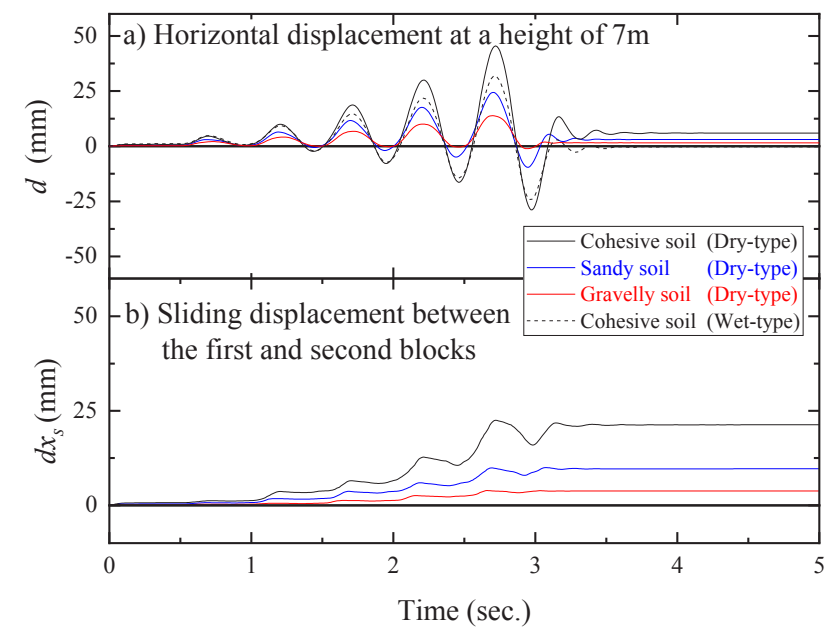

Fig. 10. Time history of response displacement of LCBW.

between a concrete block and ground behind the retaining wall. The slide or separation of a joint element was based on the Coulomb failure criterion (Fig. 6). Fig. 7 shows the input acceleration, which is a series of ten sine waves of 2 $\mathrm{Hz}$. The input acceleration was increased by 100 gal every waves up to a maximum acceleration of 500 gal.

\subsection{Simulation result}

Figure 8 shows the contour of the maximum response displacement. For the dry-type LCBW, the ground mechanical properties affected the behaviour of the blocks. In particular, the sliding between the first and the second blocks was remarkably similar to the damage to real LCBWs due to earthquake. The displacement of the blocks for the dry-type LCBW on cohesive soil was larger than that of the wet-type LCBW because of the poor integrity between blocks in the dry-type LCBW. The wet-

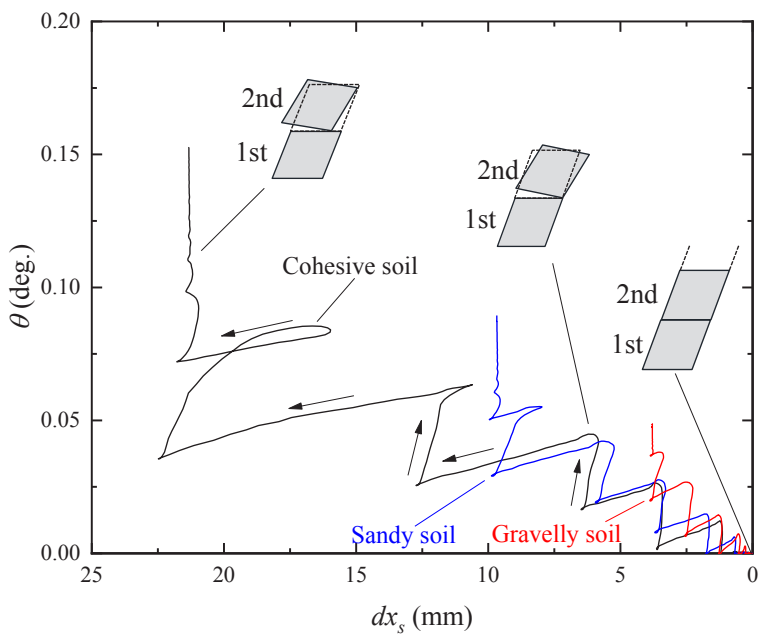

Fig. 11. Relative lateral displacement $d x_{s}$ against relative inclination angle between the first and the second blocks.

type LCBW leaned to forward unlike dry-type LCBW. For wet-type LCBW, the maximum tensile stress of frame body due to earthquake was less than of tensile strength of concrete that is generally used in retaining walls in Japan.

The relationship between shear stress and shear strain of ground is shown in Fig. 9. In the figure, a positive value of the shear strain indicates the direction toward the LCBW. Point A is located $0.3 H(2.1 \mathrm{~m})$ horizontally away from the LCBW on the slip line based on design calculation, and point B is located $2 H(14 \mathrm{~m})$ horizontally away from the LCBW (See Fig. 6). For dry-type LCBW, the shear strain of cohesive soil generated larger than the other conditions. And, for the cohesive soil of the dry-type LCBW, the shear strain $\gamma$ of 0.006 was generated, whereas for the wet-type LCBW, $\gamma$ of 0.003 was generated. This 
indicates that the performance as retaining wall of the drytype LCBW is poorer than wet-type LCBW.

Figure 10 shows the history of response displacement. For cohesive soil. horizontal displacement at the height of $7 \mathrm{~m}$ was similar of dry-type and wet-type as shown in Fig. 10 a). The sliding displacement $d x_{s}$ between the first and the second blocks markedly increased as shown in Fig. 10 b).

Figure 11 shows the relationship between the relative lateral displacement, $d x_{s}$, and the relative inclination angle, $\theta$, between the first and the second blocks. At first, the input motion caused increase of the value of $\theta$ : the upper block contacted at its heel to the lower block due to rocking. Then the upper block slid forward (increase of $d x_{s}$ ) while $\theta$ value decreasing. Such behaviour was repeated during earthquake. The values of $d x_{s}$ and $\theta$ depended on the ground mechanical properties, and became conspicuous in order of cohesive soil, sandy soil and gravelly soil. When the $\theta$ value is positive, the second block makes contact with the first block at its heel. It was found that the rocking of the second block due to earthquake causes high stress concentration at the corner of the top edge of the first block. And the first block may crack or break down, causing failure in the retaining wall. This phenomenon corresponds to the past case of LCBW damage due to an earthquake in Fig. 1 b). Therefore, it can be concluded that dry-type LCBWs are not suitable for soft ground.

\section{Conclusions}

1) Based on the results of the inclined model experiment, the LCBW model failed after the sliding between the first and second blocks occurred.

2) According to the FEM simulation of the conditions corresponding to the experiment, the behaviour of a block can be reproduced appropriately by non-linear joint elements between the blocks.

3) The dynamic analyses revealed that the movement of the blocks in the dry-type LCBW was larger than that in the wet-type LCBW because of the poor integrity between the blocks.

4) In the dry-type LCBW, the blocks slid and rocked simultaneously during seismic activity; this movement was more pronounced when the ground mechanical properties were lower.

5) Finally, it was found that the rocking of the upper block due to earthquake, concentrated high stress at the corner of the top edge of lower block. That stress may cause cracking or break down of the lower block and that may result in a failure of retaining wall.

In further study, a dynamic centrifuge model experiment of LCBW will be carried out to clarify the dynamic behaviour of LCBW. The results of the FEM simulation help to determine the conditions of dynamic centrifuge model experiments.

This research was conducted as a collaborative research between Public Works Research Institute and Japan Concrete Block Industries Association. Authors gratefully acknowledge the work of the member of retaining wall division of JCBIA.

\section{References}

1. T. Sawamatsu, N. Sato, T. Nitta, H. Miyatake, JSCE Annual Meeting.73. (2017) (In Japanese)

2. Japan road association, Guideline for road retaining walls. (2012) (In Japanese)

3. J. Izawa, J. Kuwano, Soils \& Foundations. 51 (2011)

4. F. Tatsuoka, M. Sakamoto, T. Kawamura, S. Fukushima, Soils and Foundations, 26 (1986)

5. W. Ramberg, W. T .Osgood, National Advisory Committee sor aeronautics Technical note, 902 (1943)

6. ITOCHU Techno-Solutions Corporation ,Soil plus 2017 dynamic manual, (2017) (In Japanese)

7. T. Imai, K. Tonouchi, Proceedings of the 2nd ESPT (1982)

8. Railway Technical Research Institute, Design Standards for Railway Structures and Commentary (Seismic Design) (2012) (In Japanese)

9. Fei CAI, Keizo UGAI, Introduction to Finite element Method in Geotechnical Engineering, (2013) (In Japanese)

10. The ports $\&$ harbours association of japan, Technical standards and commentaries for port and harbour facilities in japan, (2018) (In Japanese) 